REVISTA DE DERECHO UNED, NÚM. 22, 2018

\title{
EL SUFRAGIO FEMENINO EN LA II REPÚBLICA
}

\author{
WOMEN'S SUFFRAGE IN THE II REPUBLIC
}

\author{
IGNACIO ÁLVAREZ RODRÍGUEZ \\ Profesor Ayudante Doctor de Derecho Constitucional \\ Universidad de Valladolid (campus de Segovia)
}

Resumen: El texto analiza la consecución del sufragio femenino en la II República, en concreto mediante su introducción en el articulado de la Constitución de 1931, haciendo un repaso cronológico por los principales hitos que jalonaron la llegada, el reconocimiento, y el fin de una de las medidas igualitarias señeras en la democracia de entonces.

Abstract: The paper studies the women's suffrage achievement in the II Republic, mainly reached with the constitutional recognition in the 1931's Constitution. We follow a chronological path, searching for the main landmarks and goals of the awakening, implementation and end of one of the most important equality actions adopted by the Spanish democracy.

Palabras clave: sufragio, mujer, participación política, II República, Constitución de 1931.

Keywords: suffrage, women, political participation, II Republic, 1931's Constitution.

Recepción original: 15/10/2017

Aceptación original: 12/12/2017

Sumario: I. Introducción. II. El sufragismo como caldo de cultivo. II.A. En la teoría. II.B. En la práctica. III. El sufragio femenino en España. III.I. El antecedente directo de la dictadura de Primo de 
Rivera. III.2. El sufragio femenino en la Constitución de 1931 de la II República. III.2.A. La realización jurídica del sufragio femenino en tres actos. III.2.A.a. Redacción del precepto. III.2.A.b. El debate y la votación. III.2.A.c. El último envite. IV. El fin de la II República y el fin del sufragio femenino. V. Conclusiones. VI. Bibliografía.

\section{INTRODUCCIÓN}

El objetivo de estas líneas es exponer los principales hitos que jalonaron el sufragio femenino en la historia española más reciente, específicamente en la II República ${ }^{1}$. Para ello se expone en primer lugar el caldo de cultivo de dicha reivindicación, que no es otro que la corriente política denominada sufragismo ${ }^{2}$. Posteriormente se abordan los avatares del reconocimiento del mismo en la II República, en concreto en la Constitución de $1931^{3}$, repasando sus antecedentes directos, estudiando su proceloso desarrollo y adopción, con especial énfasis en los debates parlamentarios ${ }^{4}$. También se dedican algunas líneas a los momentos finales de tal derecho, cuyo final fue consecuencia, claro está, del fin del propio régimen republicano. Todo ello finaliza con unas conclusiones que sometemos a mejor juicio de los expertos.

\footnotetext{
${ }^{1}$ Abordan en profundidad diferentes aspectos de dicho régimen VVAA; Estudios sobre la II República Española, Tecnos, Madrid, 1975. También RAMÍREZ JIMÉNEZ, M; Las reformas de la II República, Túcar, Madrid, 1977.

${ }^{2}$ Contiene datos y reflexiones interesantes sobre este periodo GÓMEZ, FERNÁNDEZ, I; Una Constituyente feminista. ¿Cómo reformar la Constitución con perspectiva de género?, Marcial Pons-Fundación Manuel Giménez Abad, Madrid, 2017, pág. 27 y ss.

${ }^{3}$ Desde el Derecho Constitucional puede verse VARELA SUANZES-CARPEGNA, J; Política y Constitución en España (1808-1978), CEPC, Madrid, 2014 (2. ${ }^{a}$ edición), pág. 735 y ss; TOMÁS VILARROYA, J; Breve historia del constitucionalismo español. CEPC, Madrid, 2012 (13. ${ }^{\mathrm{a}}$ edición), pág. 121 y ss; TORRES DEL MORAL, A; Constitucionalismo histórico español, Servicio de Publicaciones de la Facultad de Derecho-UCM, Madrid, 2004 (5. ${ }^{\text {a }}$ edición), pág. 182 y ss.; VERA SANTOS, J.M; Las Constituciones de España. Constituciones y otras leyes y proyectos políticos de España. Thomson-Civitas, Cizur Menor (Navarra), 2008, pág. 392 y ss; y OLIVER ARAUJO, J; El sistema político de la Constitución Española de 1931, Ediciones UIB, Palma de Mallorca, 1999; también resulta de utilidad e el trabajo de GARCÍA ATANCE, M. ${ }^{\mathrm{a}}$ V; «Crónica parlamentaria sobre la Constitución de 1931». Revista de Derecho Político, n. ${ }^{\circ} 12,1981-1982$, págs. 295-306. Obra de consulta imprescindible es la de JULIÁ, S; La Constitución de 1931, Iustel, Madrid, 2009. También es muy ilustrativa la de PÉREZ SERRANO, N; La Constitución Española, 9 diciembre 1931: Antecedentes, Texto, Comentarios, Editorial Revista de Derecho Privado, Madrid, 1932.

${ }^{4}$ Ver también, entre otros, MONTERDE GARCÍA, J.C; «Algunos aspectos sobre el voto femenino en la II República española: debates parlamentarios», Anuario de la Facultad de Derecho, n. ${ }^{\circ}$ 28, 2010, págs. 261-277.
} 


\section{EL SUFRAGISMO COMO CALDO DE CULTIVO}

Un detalle que se suele pasar por alto con cierta frecuencia es que el sufragio femenino se consiguió a través de diversas luchas, protagonizadas en buena medida por asociaciones y partidos feministas. El consenso entre élites, allá donde llegó, llegó después. A lo largo del siglo XIX, el denominado «movimiento sufragista» combatió por conseguir el voto de la mujer, ayudando a crear las condiciones políticas y sociales para sentar las bases de la igualdad política, senda que tuvo su momento de gloria en su reconocimiento, sobre todo en el periodo de entreguerras 5 .

La doctrina sitúa la historia del feminismo sufragista en tres períodos: de 1848 a 1871 , de 1871 a 1900 y de 1900 hasta el periodo de entreguerras $^{6}$. En el primer periodo cristalizan las asociaciones más relevantes que reclamaban la igualdad entre mujeres y hombres en Inglaterra y EEUU, luchando contra los tópicos que se atribuían a la esencia femenina. En el segundo periodo, algunas reivindicaciones civiles de las mujeres son reconocidas, pero todavía siguen fuera de la esfera pública y política. Ya en el tercero la mujer alcanza el derecho de sufragio masivamente, en países como EEUU, Inglaterra o Austria. Al mismo contribuyeron diversos planteamientos teóricos y concretas acciones prácticas.

\section{II.A. En la teoría}

Desde casi siempre han existido pensadores y pensadoras preocupadas por la situación de la mujer en la sociedad ${ }^{7}$. Merece la pena destacar a dos: a Olimpia de Gouges, la escritora que redactó la Declaración de los derechos de la mujer y de la ciudadana en 1791;

${ }^{5} \mathrm{Vid}$. COBO, R; «Repensando la democracia: mujeres y ciudadanía», en COBO, R (ed.); Educar en la ciudadanía. Perspectivas feministas, Los libros de la catarata, Madrid, 2008, pág. 30 y ss.

${ }^{6}$ MIYARES, A; «El sufragismo», en AMORÓs, C y DE MIGUEL, A (eds.) Teoría feminista: de la Ilustración a la globalización. De la Ilustración al segundo sexo, Minerva, Madrid, 2005, págs. 245-293. También puede verse MARRADES PUIG, A; "Los derechos políticos de las mujeres: evolución y retos pendientes», Cuadernos de la Cátedra Fadrique Furió Ceriol, n. ${ }^{\circ}$ 36/37, 2001, págs. 195-214; y PÉREZ GARZÓN, J.S; Historia del Feminismo, Libros de la Catarata, Madrid, 2011.

${ }^{7}$ Entre nosotros destaca el ejemplo de POSADA, A; Feminismo, Ediciones Cátedra, Oviedo, 1994 (2. ${ }^{a}$ edición). La primera edición de esta obra fue editada en 1899, por Ricardo Fe (Madrid). En el mismo sentido se pronuncia periodo GÓMEZ, FERNÁNDEZ, I; op. cit., pág. 41. 
y a Mary Wollstonecraft, con su Vindicación de los derechos de la mujer, en $1792^{8}$.

La escritora francesa vino a mostrar con su Declaración que el proyecto ilustrado que alumbró la revolución francesa no contemplaba a las mujeres, excluyéndola de forma categórica de la esfera pública. Tal y como se ha dicho por voces autorizadas, «el feminismo es un hijo no querido de la Ilustración ${ }^{9}$. Por eso toma la Declaración de derechos del hombre y del ciudadano de 1789 y la feminiza, aplicando lo dispuesto en ella exclusivamente a las mujeres y dejando claro que la propia revolución era un obstáculo para los avances igualitarios ${ }^{10}$. Su atrevimiento, qué duda cabe, la condujo al cadalso en 1793.

Con los sucesos revolucionarios franceses como punto de referencia, Inglaterra vería a la escritora Mary Wollstonecraft realizar un durísimo alegato contra los prejuicios de la época hacia la mujer, reclamando para ella la condición de ser racional, ser humano igual al hombre y, en consecuencia, acreedora de los mismos derechos y posibilidades de desarrollo personal. En definitiva, viene a reclamar una reconstrucción de las bases sobre las que hasta ese momento se habían constituido las sociedades políticas, teniendo presente también a la mujer, y a todos los efectos, para alcanzar dicha tarea. El objetivo no se podía llevar a cabo sin darle la importancia merecida a los instrumentos educativos; de muestra, un botón en la introducción de su libro: «La profunda convicción de que la educación descuidada de mis compañeras es la gran fuente de desgracia que deploro, así como de que a las mujeres, en particular, se las hace débiles y desgraciadas por una variedad de causas concurrentes, derivadas de una conclusión precipitada» ${ }^{11}$.

${ }^{8}$ Vid. GARRIDO GÓMEZ, I; «Los movimientos feministas». En CARMONA CUENCA, E (coord.); Diversidad de Género e Igualdad de Derechos, Tirant lo blanch, Valencia, 2012, pág. 54.

${ }^{9}$ Vid. VALCÁRCEL, A; "La memoria colectiva y los retos del feminismo", Naciones Unidas, Serie Mujer y desarrollo, n. ${ }^{\circ} 31,2001$, pág. 8. De la misma autora se puede consultar «El derecho al mal» (Apéndice), en Sexo y filosofía. Sobre «mujer»y "poder», Anthropos, Barcelona, 1994, pág. 162 y ss. Vid. también AMORÓS, C; «Feminismo e Ilustración», en CAPEL, R (ed.); Historia de una conquista: Clara Campoamor y el voto femenino, Ayuntamiento de Madrid-Dirección General de la Mujer, Madrid, 2007, págs. 34-49.

${ }^{10}$ El epílogo de la Declaración redactado por De Gouges no deja lugar a dudas: «¡Oh mujeres! ¡Mujeres! ¿Cuándo dejaréis de estar ciegas? ¿Qué ventajas habéis obtenido de la revolución? Un desprecio más marcado, un desdén más visible». El documento se ha consultado el 5 de noviembre de 2017 aquí: http:// feministasconstitucional.org/portfolio-items/sobre-la-declaracion-de-los-derechos-dela-mujer-y-de-la-ciudadana/. Sobre aquélla puede verse BLANCO CORUJO, O; Olimpia de Gouges (1748-1793). Madrid, Ediciones del Orto, 2000.

${ }^{11}$ WOLLSTONECRAFT, M; Vindicación de los derechos de la mujer, Istmo, Madrid, 2005, pág. 47. 
Además, otras corrientes ideológicas de la época también tuvieron a la mujer en el centro de sus preocupaciones. Sería el caso del socialismo utópico, encabezado por Saint-Simon, Owen y Fourier, que elaboraron diferentes modelos de convivencia social que permitirían a mujeres y hombres alcanzar la libertad e igualdad «plenas». También es el caso del liberalismo encarnado por John Stuart Mill. Este presentó, en 1866, una petición a favor del voto femenino en la Cámara de los Comunes, junto a Henry Fawcet, petición que fue rechazada y que dio lugar a la formación de la Nacional Society for Woman's Suffrage (NSWS), primera asociación declaradamente sufragista y que continuó presentando, a lo largo de dos décadas y a través de liberales de izquierda, proyectos de ley a favor del sufragio femenino. Por lo demás, Mill dejó puntual constancia del que se considera un clásico dentro de los textos feministas ${ }^{12}$.

Otro de los instrumentos teóricos que servirían al movimiento sufragista para sus reivindicaciones fue la Declaración de Séneca Falls, elaborada en EEUU el 19 de julio de 1848 por doscientas mujeres que pusieron especial énfasis, no sólo en denunciar de forma general aquellas desigualdades que arraigaban en la sociedad norteamericana entre mujeres y hombres, sino también en reclamar vehementemente la igualdad política y, en consecuencia, el derecho al voto para el colectivo femenino ${ }^{13}$. Así queda plasmado sin ambages en la redacción de la misma, como muestra el tercer punto del documento, en el que se dice "Que la mujer es igual al hombre —que así lo pretendió el Creador-y que por el bien de la raza humana exige que sea reconocida como tal»o, por ejemplo, al observar el punto noveno del mismo: "Que es deber de las mujeres de este país asegurarse el sagrado derecho del voto».

Tal Declaración dio lugar a la creación de la National Woman Suffrage Association (NWSA), asociación que tuvo un papel crucial

${ }^{12}$ La Exposición de Motivos de nuestra vigente Ley de Igualdad de 2007 realiza una referencia explícita al pensamiento de Mill, para quien la igualdad es esa "perfecta igualdad que no admitiera poder ni privilegio para unos ni incapacidad para otros». Con la ayuda inestimable de su amiga y esposa Harriet Taylor, publicó su obra "The Subjection of Women», en 1869, en la que analiza las desigualdades que anidan del momento, reclamando la puesta en marcha de acciones para luchar contra las mismas. Vid. STUART MILL, J; Libertad. Gobierno representativo. Esclavitud femenina, Tecnos, Madrid, 1969, pp. 363-436. Una versión reciente, con prólogo, traducción y notas de Carlos Mellizo, en STUART MILL, J; El sometimiento de la mujer, Alianza Editorial, Madrid, 2010.

${ }^{13}$ Dicho énfasis no sólo se vio traducido en enérgicas reivindicaciones políticas, sino que a la propia Declaración se la conoce también como «Declaración de Sentimientos». Vid. MIYARES, A; op. cit., pág. 254.

(C) UNED. Revista de Derecho UNED, núm. 22, 2018 
a la hora de difundir el mensaje, desde una óptica más bien radical. Debido al mismo surge la escisión - la American Woman Suffrage Association (AWSA) - que abogaba por una táctica gradualista. Finalmente consiguieron conciliar posturas, estrategias y opiniones, dando lugar a la fusión de ambas asociaciones en la denominada National American Woman Suffrage Association (NAWSA), en el año 1890.

\section{II.B. En la práctica}

Pero ha quedado dicho más arriba que el movimiento sufragista no se limitó a la producción de argumentos teóricos. Haciendo bueno su nombre, estos fueron llevados a la práctica, con mayor o menor éxito, por un sinfín de asociaciones, organizaciones y partidos que tenían como nexo de unión la reivindicación del sufragio para la mujer. El siglo XX verá cómo dicha exigencia se satisfará en buena parte de los Estados europeos, sin escatimar un ápice de sangre, sudor y lágrimas. Los principales focos donde se produjeron los hechos fueron Inglaterra, EEUU y Francia; a tales casos dedicaremos las siguientes líneas.

En Inglaterra, las feministas del país marcaron la pauta internacional en la lucha por el sufragio femenino ${ }^{14}$. De hecho, la primera proposición para el voto femenino se registra por Mary Smith en 1832 en el Parlamento Británico ${ }^{15}$. Pasados unos cuanto años, bajo el lema "Votes for Women!», las sufragistas ejecutaron una serie de acciones reivindicando tal derecho, algunas de ellas de gran impacto entre la opinión pública, como tendremos ocasión de ver. Allá por el año 1909, casi cien organizaciones feministas se federaron en torno a la National Union of Women's Suffrage. Dentro de esta, destacó la Women's Social and Political Union (WSPU), liderada por una de las feministas inglesas más importantes de su reciente historia: Emmeline Pankhurst. De dilatada experiencia política y defensora incansable de los derechos de las mujeres, llegó a militar en el Partido Liberal, pero terminó por abandonarlo y, junto a algunas mujeres laboristas, fundó la WSPU. Después de la negativa de aquél de llevar al Parlamento su reivindicación del derecho de voto femenino, lidera numerosos actos a pie de calle, con duros enfrentamientos entre mujeres y policías, produciéndose múltiples disturbios y encarcelamientos,

${ }^{14}$ Una visión sumamente interesante se encuentra en la película Sufragistas, de Sarah Gavron y Abi Morgan (Gran Bretaña, 2015).

${ }^{15}$ Vid. CAPEL MARTINEZ, R; "La conquista del voto femenino», Andalucía en la Historia, n. ${ }^{\circ} 13,2006$, pág. 47. 
hasta que llegó el fatal desenlace: el 5 de junio de 1911 los asistentes a una carrera de caballos vieron cómo Emily Davidson, de 35 años, se lanzó en plena carrera a la pista, como gesto simbólico que pusiera a las clases acomodadas - y la sociedad inglesa en general- ante la triste realidad de la subyugación femenina. Fue arrollada por los animales y murió tres días después en el hospital, convirtiéndose así en la primera mártir del sufragismo.

Posteriormente a dicho acontecimiento, hubo escisiones dentro del movimiento sufragista, abogando ciertos sectores por una desobediencia civil sin violencia (encadenamiento al Parlamento, lanzamiento de octavillas, etc.); incluso una de las hijas de Emmeline Pankhurst, Sylvia, lideró uno de los grupos escindidos. El estallido de la I Guerra Mundial dejó en suspenso la adopción del sufragio femenino, la actividad militante desapareció y las mujeres pasaron a hacerse cargo de aquellas tareas que hacían posible que Gran Bretaña siguiera subsistiendo sin apenas varones, ya que habían marchado a hacer la guerra. En mayo de 1917, llega el momento decisivo: después de tantas luchas y penurias, se aprueba por el Parlamento Británico el voto para las mujeres de al menos treinta años (cinco más que la edad exigida para los varones), quedando ambos sexos equiparados plenamente en 1928. El voto femenino había sido conquistado ${ }^{16}$.

En EEUU el esquema es similar al inglés ${ }^{17}$. La reivindicación del sufragio femenino tuvo también tintes violentos, dramáticos, encarcelamientos y raudales de violencia popular y policial. El objetivo era conseguir el voto para las mujeres a nivel federal mediante la aprobación de la XIX enmienda a la Constitución; a tal fin, se fundó el Partido Nacional de la Mujer, liderado por Alice Paul, cuya principal actividad fue hacer campaña en contra de la reelección del Presidente Wilson, que se saldó con un claro fracaso. Ante tal situación, el movimiento se radicalizó, produciéndose disturbios violentos y encarcelamiento de sufragistas. Pero en EEUU, la NAWSA y su líder desde 1915, Carrie Chapman, observaron que quizás el triunfo del sufragio femenino vendría adoptando una estrategia de mínimos, no de máximos, por lo que insiste en la idea de que el voto de la mujer fuera alcanzado Estado por Estado y no a nivel federal, como planteaba el Partido Nacional de la Mujer. Hasta ese momento, algunos Estados norteamericanos habían reconocido ese derecho, referéndum mediante (Wyoming, en 1869, Utah en 1870, Colorado en 1893 o Idaho,

\footnotetext{
${ }^{16}$ Para esta parte seguimos el esquema de MIYARES, A; op. cit, pág. 288 y ss.

${ }^{17}$ Vid. AGUADO, A; «Ciudadanía, mujeres y democracia», Historia Constitucional, n. ${ }^{\circ} 6$ (2005), pág. 24 y ss.
} 
en 1896.). Finalmente, el 19 de enero de 1917, Wilson anuncia su apoyo a la reivindicación sufragista, y la Cámara de Representantes aprueba la 19. ${ }^{\text {a }}$ enmienda por mayoría de dos tercios. Una vez que tuvo lugar la aprobación del Senado y la preceptiva consulta a los Estados, el 18 de agosto de 1920 los EEUU plasmaron constitucionalmente el derecho de sufragio femenino mediante la ratificación de la XIX Enmienda: "The right of citizens of the United States to vote shall not be denied or abridged by the United States or by any State on account of sex. Congress shall have power to enforce this article by appropriate legislation».

En Francia ${ }^{18}$, la cuna de la Ilustración y de las promesas incumplidas para la mujer, según hemos visto en palabras de Olimpia de Gouges ${ }^{19}$, también prendió la mecha del sufragismo inglés, encarnado aquí por Hubertine Auclert y Madeleine Pelletier. Durante las primeras décadas del siglo Xx se produjeron enérgicos combates en favor de la reivindicación sufragista, llegando a irrumpir en la Asamblea Nacional y finalizando alguna de las manifestaciones que convocaron con brutales enfrentamientos entre policías y mujeres. Terminada la Gran Guerra se debate - y rechaza- por dos veces la cuestión del voto femenino (1919 y 1922). Bajo los auspicios de la IV República, el sufragio femenino queda definitivamente incorporado al sistema político francés, en el año 1946, a imagen y semejanza de lo que ocurrió en buena parte de los países del mundo: la concesión del voto a la mujer después de finalizada la II Guerra Mundial ${ }^{20}$.

${ }^{18} \mathrm{Al}$ hilo de este país también expone ideas sugerentes AGUADO, A; «Ciudadanía, mujeres y democracia», Historia Constitucional, n. ${ }^{\circ} 6$ (2005), pág. 18 y ss.

${ }^{19}$ Cabe establecer cierto paralelismo entre la opinión de De Gouges y lo ocurrido respecto a la no aplicación a la mujer de los valores de la revolución francesa, y la visión que sostiene Susan Mendus y la teoría de la democracia. En definitiva, la mayor parte del feminismo observa cómo aquéllos lo fueron en tanto en cuanto masculinos: el ámbito público estaba restringido al varón, quedando la mujer excluida de la retórica tríada igualdad, libertad y fraternidad. Mendus encuentra justificado el escepticismo de cierto sector feminista respecto de la democracia, debido a que la teoría democrática se habría comprometido con unos ideales que en definitiva aseguran que la mujer va a estar siempre en desventaja, por lo que, desde sus orígenes, la democracia ha venido aliándose con unos valores que subyugan a la mujer en el pasado, en el presente y, posiblemente, en el futuro. Vid. MENDUS, S; "La pérdida de la fe: feminismo y democracia», en DUNN, J (Dir.); Democracia. El viaje inacabado (508 a.C-1993 d.C), Tusquets, Barcelona, 1995, págs. 222-235.

${ }^{20}$ Para conocer las fechas en las que el voto femenino fue plasmado por los diferentes regímenes políticos a lo largo y ancho del mundo, se pueden consultar los "Anexos» elaborados por Jaume Molins, en SEVILLA MERINO, J; Mujeres y ciudadanía: la democracia paritaria, Institut Universitari d'Estudis de la DonaUniversitat de València, 2004, págs. 155 y 156. 


\section{EL SUFRAGIO FEMENINO EN ESPAÑA}

El sufragio femenino en España se consiguió, de forma completa, en la II República. Hasta entonces sólo existieron remedos y simulacros del mismo, siempre limitado hasta la extenuación ${ }^{21}$. Repasaremos ahora el antecedente directo de dicho reconocimiento, para después prestar atención a cómo se logró su plasmación constitucional definitiva.

\section{III.1. El antecedente directo de la dictadura de Primo de Rivera}

Antes de comenzar el análisis de lo que sucedió en la II República, es necesario hacer una breve alusión al antecedente inmediato ${ }^{22}$. En ese sentido, y por extraño que pueda parecer, será en la Dictadura del General Primo de Rivera ${ }^{23}$ donde se encuentren algunas circunstancias que se apuntalaron definitivamente mediante la Constitución de 1931. Veamos ${ }^{24}$.

Efectivamente, mandando Primo de Rivera en 1927, se planteó la posibilidad de convocar elecciones y constituir acto seguido una Asamblea Nacional. Mediante Real Decreto publicado en la Gaceta de Madrid quedó recogido el voto para todas las mujeres mayores de 23 años y jurídicamente libres (no casadas), temiéndose que la extensión del sufragio al colectivo femenino quebrara la institución familiar ${ }^{25}$.

Las razones que llevaron al régimen a conceder, de forma limitada, este derecho, no aparecen claras. Pudieron influir dos hechos; en primer lugar, los movimientos sufragistas desarrollados en Gran Bretaña y EEUU, que conquistaron el voto femenino en 1918 y 1920, respectivamente, quizás contribuyeron a que aquél pudiera mostrarse

${ }^{21}$ Por todos, vid. SÁNCHEZ COLLANTES, S; «Antecedentes del voto femenino en España: el republicanismo federal pactista y los derechos políticos de las mujeres (1868-1914)»; Historia Constituciónal, n. ${ }^{\circ} 15$ (2014), págs. 445-469.

${ }^{22}$ Para entender el contexto y la situación global de aquélla España puede verse VACA DE OSMA, J.A; Historia de España para jóvenes del siglo XXI, Ediciones Rialp, Madrid, 2010 (4. ${ }^{a}$ edición), págs. 361 y ss.

${ }^{23}$ Voces autorizadas consideran preferible calificar al periodo que va de 1923 a 1931 de «reinado dictatorial» antes que de «Dictadura (de Primo de Rivera)», puesto que Alfonso XIII fue en todo caso Jefe de Estado a lo largo de dicho periodo. Vid. PÉREZ-PRENDES MUÑOZ-ARRACO, J.M; Escritos de Historia Constitucional Española, Marcial Pons, Madrid, 2017, pág. 323.

${ }^{24}$ Testimonio siempre interesante es el de DE BURGOS, C; La mujer moderna y sus derechos, Ayuntamiento de Madrid, 2007; (1. ${ }^{a}$ edición: Editorial Sempere, 1927), págs. 290 y ss.

${ }^{25}$ Vid. DURÁN Y LALAGUNA, P; El voto femenino en España, Asamblea de Madrid, Madrid, 2007, pág. 18 y ss.

(C) UNED. Revista de Derecho UNED, núm. 22, 2018 
como un defensor de la causa sufragista, otorgándole mayor respeto y simpatía internacional; en segundo lugar, en los primeros comicios en los que participaban las mujeres, y tal y como sucedió en el caso alemán, la opción que triunfó fue la conservadora, por lo que Primo, al ver tales resultados, pudo ver en ellos un antecedente positivo que quizá se imitara en España ${ }^{26}$.

Junto a estas dos razones, quizás existiría una tercera: la línea favorable que desde ciertos sectores católicos se fraguó a favor de la concesión del voto femenino, tal y como quedó ilustrado en el periódico madrileño El Debate, de 22 de noviembre de 1928, en los siguientes términos: "A las derechas españolas, semejante reforma, lejos de asustarles les debe merecer decidido apoyo, puesto que la inmensa mayoría de las mujeres de España son cristianas, católicas». Se ponían las bases para la unión entre derecha, catolicismo y voto femenino, con la esperanza de que las dos primeras corrientes pudieran orientarlo convenientemente.

Además, no se puede obviar la influencia, aunque relativa no deja de ser importante, de las asociaciones feministas que comienzan a gestarse y desarrollarse en la época, unido a la evolución del estatus social de la mujer ${ }^{27}$. Las asociaciones católicas femeninas (fundamentalmente de clase alta y dedicadas a labores de caridad) ya no estarán solas en el panorama asociativo español del sector ${ }^{28}$; se crea la Asociación Nacional de Mujeres Españolas (ANME) en 1918, una de las organizaciones más importantes y activas a la hora de reclamar el sufragio femenino (contando en sus filas con mujeres tan importantes como Victoria Kent y Clara Campoamor, entre otras ${ }^{29}$. Respecto a aquella evolución, existen ciertos indicios que muestran una serie de mejoras en las condiciones de vida de las mujeres, al menos desde el punto de vista intelectual: en 1927 ya se contaban 1244 mujeres en la Universidad, había aumentado su participación activista y sindical, y se habían creado numerosos Institutos de Enseñanza Media para chicas en Barcelona y Madrid ${ }^{30}$.

${ }^{26}$ Vid. CAPEL, R; El sufragio femenino en la II República Española, Granada, Universidad de Granada, 1992.

${ }^{27} \mathrm{Vid}$. FIGUERUELO BURRIEZA, A; «Setenta y cinco años de sufragio femenino en España. Perspectiva constitucional». Criterio Jurídico, n. ${ }^{\circ}$ 7, 2007, pág. 150 y ss.

${ }^{28}$ Por todos, ver ALZAGA VILLAMIL, Ó; La primera democracia cristiana en España, Ariel, Barcelona, 1973, pág. 242 y ss.

${ }^{29}$ Vid. SCANLON, G.M; «El movimiento feminista en España, 1900-1985: logros y dificultades». En ASTELARRA, J (comp); Participación política de las mujeres, CIS, Madrid, 1990, pág. 87 y ss.

${ }^{30}$ Vid. ÁLVAREZ-PIÑAR, M (y otras); El voto femenino en España, Subdirección General de Cooperación-Instituto de la Mujer, 1995, pág. 68. 
A pesar de todo, el voto femenino en este periodo no tuvo repercusiones prácticas. Las elecciones proyectadas no llegan a celebrarse, nada sucedió más allá del papel. Aún así, se llevaron a cabo ciertas operaciones «cosméticas» por parte del régimen, con el nombramiento de trece diputadas para formar parte de la Asamblea Nacional, abierta el 11 de octubre de $1927^{31}$.

El 28 de enero de 1930, Primo de Rivera presenta su dimisión al rey Alfonso XIII. La monarquía comenzaba a sentirse sola. El rey decide que la supervivencia del sistema pasa por volver al sistema de la Restauración canovista. El gobierno Berenguer convoca unas elecciones generales que, finalmente, fueron municipales por decisión del gobierno Aznar, bajo cuya Presidencia tuvieron lugar el 12 de abril de 1931. La sorpresa se produjo: a la clara y esperada victoria monárquica en las zonas rurales se opuso una firme victoria republicana en las ciudades ${ }^{32}$. La situación fue confusa ya que unos no esperaban perder ni los otros ganar, pero aún así, Alfonso XIII decide abandonar el país y el 14 de abril de 1931 queda proclamada la II República Española, recibida con alborozo popular y sin derramamiento de sangre.

El Ministro de la Gobernación Miguel Maura elabora un Decreto para regular las elecciones a la Asamblea Constituyente; Asamblea cuya principal misión es redactar un Proyecto de Constitución discutido y aprobado por el Parlamento Republicano ${ }^{33}$. A los efectos que aquí interesan, dicha norma, además de rebajar la edad electoral a los 25 años y cambiar las circunscripciones unipersonales por las provinciales, concede a la mujer el derecho de ser elegida (sufragio pasivo que no activo) para las Cortes constituyentes. Celebradas las elecciones el 28 de junio de 1931, en primera vuelta, y el 5 de julio en segunda, la composición que arrojan los resultados definitivos muestra una Cámara parlamentaria de mayoría republicana de izquierda y centrista (socialistas y radicales eran las «minorías mayoritarias», con 116 y 90 escaños respectivamente). De un total de 470 diputados elegidos,

${ }^{31}$ Estudiosos de dicho periodo acreditan cómo se prescindió de todo proceso electoral. Vid. GARCÍA CANALES, M; El problema constitucional en la Dictadura de Primo de Rivera, Centro de Estudios Constitucionales, Madrid, 1980, pág. 94.

32 En Madrid se llega a hablar de «triunfo avasallador» de la coalición entre republicanos y socialistas. Vid. VILLALAÍN, P; Las elecciones municipales de 1931 en Madrid, El Avapiés, Madrid, 1987, pág. 91 y ss.

${ }^{33}$ Conviene tener presente que en esa primera época republicana, los partidos políticos eran «poco estructurados, de organización casi inexistente (y venían a) definirse más por aquello frente a lo que estaban que por aquello que querían». Así lo expresa RAMÍREZ, M; «La agregación de intereses en la II República», en VVAA; Estudios sobre la II República Española, Tecnos, Madrid, 1975, pág. 37.

(C) UNED. Revista de Derecho UNED, núm. 22, 2018 
sólo dos fueron mujeres: Victoria Kent, por Madrid, en las listas del Partido Radical Socialista y Clara Campoamor, también por Madrid, en las listas del Partido Republicano Radical ${ }^{34}$. Ellas dos serán las principales protagonistas de un debate que finaliza con la victoria de los argumentos a favor del sufragio femenino, como veremos a continuación ${ }^{35}$.

\section{III.2. El sufragio femenino en la Constitución de 1931 de la II República}

Será con la Constitución de 1931 cuando el sufragio universal se haga realidad por primera vez en nuestra Historia ${ }^{36}$. Hasta llegar a verlo rubricado en la Norma tuvieron que pasar bastantes cosas ${ }^{37}$, que aquí hemos sintetizado en tres actos. En primer lugar, la redacción del precepto. En segundo lugar, el debate; y en tercer lugar, el último envite que tuvo que sufrir ese artículo 36 en su redacción definitiva ${ }^{38}$.

${ }^{34}$ A finales de 1931 ingresa en la Cámara por el Partido Socialista Margarita Nelken. Esta última no puedo tomar parte en el debate constituyente ya que no fue hasta diciembre cuando se le reconoce por los Tribunales su escaño por Badajoz (por el Partido Socialista). Vid. PEÑA GONZÁLEZ, J; «El voto femenino», Real Academia de Córdoba de Ciencias, Bellas Letras y Nobles Artes, n. ${ }^{\circ} 160$, 2011, pág. 320 y ss. A modo de anécdota, decir que ese día en el Parlamento «alguien dijo: Es la primera mujer que viene a las Cortes» (lo decían por molestar a la Campoamor o a la Kent»). Vid. AZAÑA, M; «Diarios»; en AZAÑA, M (edición de JULIÁ, S); Obras Completas, vol. 3, CEPC, Madrid, 2007, pág. 885.

${ }^{35}$ Vid. SCANLON, GM; op. cit., págs. 92 y 93; y GILBAJA CABRERO, E; «Clara Campoamor y el sufragio femenino en la Constitución de la Segunda República», Asamblea: Revista Parlamentaria de la Asamblea de Madrid, n. ${ }^{\circ}$ 29, 2013, págs. 293312.

${ }^{36} \mathrm{Vid}$. ESCUDERO ALDAY, R; "Las huellas del neoconstitucionalismo. Democracia, participación y justicia social en la Constitución Española de 1931». En GORDILLO, L; MARTÍN, S; y VÁZQUEZ, V (Dirs.); Constitución de 1931: estudios jurídicos sobre el momento republicano español, Marcial Pons, Madrid, 2017, pág. 111 y ss; y CLAVERO, B; Manual de Historia Constitucional de España, Alianza, Madrid, 1992, pág. 198.

${ }^{37}$ Cosas que no sólo tuvieron que ver con el tema concreto, claro está. Por ejemplo, cómo se enrareció el ambiente en asuntos clave para el país. Por poner un ejemplo, con la educación. Sobre tal extremo véase TORRES MURO, I; «La educación en tres momentos constitucionales $(1812,1931,1978)$ », Revista Española de Pedagogía, n. ${ }^{\circ}$ 253, 2012, págs. 401-416.

${ }^{38}$ Ver MONTERDE GARCÍA, J.C; «Algunos aspectos sobre el voto femenino en la II República española: debates parlamentarios», Anuario de la Facultad de Derecho, n. ${ }^{\circ} 28,2010$, págs. 261-277. 


\section{III.2.A. Redacción del precepto}

Se crea una Comisión presidida por el socialista Jiménez de Asúa y formada por veinte miembros, entre los cuales figura Campoamor. Uno de los principales obstáculos que tiene que abordar dicho órgano es la redacción del artículo 23 del anteproyecto constitucional, que rezaba así: «No podrán ser fundamento de privilegio jurídico: el nacimiento, la clase social, la riqueza, las ideas políticas y las creencias religiosas. Se reconoce, en principio, la igualdad de derechos de los dos sexos. El Estado no reconoce los títulos y distinciones nobiliarios». Conjugando esto con lo que decía el artículo 34 del anteproyecto, quedaba abierta la puerta a una futura limitación legal de la igualdad política. Esta norma decía así: «Los ciudadanos de uno y otro sexo, mayores de veintiún años, tendrán los mismos derechos electorales conforme determinen las leyes». Intuyendo el peligro que se avecinaba, Campoamor aboga por agregar al artículo 23 la expresión "el sexo» como otra de las fuentes sobre las cuales no cabría fundamentar privilegio alguno, así como eliminar el término «en principio ${ }^{39}$. A pesar de sus esfuerzos, la iniciativa no es apoyada, por lo que habrá que esperar a la toma en consideración de los preceptos mencionados por el Pleno del Congreso de los Diputados para conocer cual será su redacción definitiva. Aún así, ya comienzan a vislumbrarse los primeros indicios que apuntan a que la plasmación del sufragio femenino en el texto constitucional no será tarea fácil. A título de ejemplo, el diputado Álvarez Buylla argumenta que «el voto de las mujeres es un elemento peligrosísimo para la República (...) la mujer española (...) no se ha separado de la influencia de la sacristía y el confesionario (...) a la mujer puede dársele el derecho pasivo, pero nunca el derecho a ser electora ${ }^{40}$. En línea semejante, el diputado Ossorio y Gallardo alega que el voto de la mujer casada llevaría la perturbación a los hogares, por lo que se hacía necesaria su restricción ${ }^{41}$. No será la última vez que las paredes del Congreso de los Diputados escuchen argumentos semejantes. Finalmente se apoya el texto de la Comisión y se pasa el proyecto para su discusión, contando con apoyos suficientes para superar el trance.

${ }^{39}$ Vid. MONTERDE GARCÍA, J.C; op. cit., pág. 263.

${ }^{40} \mathrm{Vid}$. VÁLCARCEL, A; «El voto femenino en España. La Constitución del 31 y Clara Campoamor». Estudio Preliminar en El debate sobre el voto femenino en la Constitución de 1931, Congreso de los Diputados. Madrid, 2002, pág. 33.

${ }^{41}$ Diario de Sesiones de Cortes, n. ${ }^{\circ}$ 30. Martes 1 de septiembre de 1931, págs. 1619. En adelante, las frases de diputados y diputadas que aparezcan entrecomilladas pertenecen a expresiones recogidas en las actas de dicho Diario.

(C) UNED. Revista de Derecho UNED, núm. 22, 2018 
III.2.B. El debate y la votación

El debate puede estructurarse en dos grandes momentos ${ }^{42}$. El primero es el de la fijación de posiciones de las distintas partes, mientras que el segundo alude al intercambio dialéctico protagonizado por Kent y Campoamor ${ }^{43}$.

El 30 de septiembre de 1931 comienzan a perfilarse las distintas opciones y argumentos. En lo que se refiere al artículo 23, se acaba aceptando la petición de la segunda de eliminar la expresión «en principio» (siendo aquí apoyada por la primera). Habiendo resuelto dicho punto, se discute la cuestión de la edad electoral: los socialistas defienden que sea de veintiún años, que era lo acordado en la redacción del anteproyecto, mientras que la Comisión respaldaba situarla en los veintitrés años. Se procede a la votación y el Partido Socialista es derrotado, quedando definitivamente fijada la edad electoral en veintitrés años.

En lo que se refiere al artículo 34, se presentan dos enmiendas a la redacción que se ha expuesto en líneas posteriores, una del diputado Ayuso y otra del diputado Guerra del Río. El primero de ellos, diferenciando entre sexo y edad, dejó dicho que: «Los ciudadanos varones desde los veintitrés y las hembras desde los cuarenta y cinco tendrán los mismos derechos electorales ${ }^{44}$. ¿Qué razones aportó el diputado para defender dicha enmienda? Cuanto menos sorprendentes, alegando con supuesta base científica, "¿No puede estar y de hecho está disminuida en algún momento la voluntad, la inteligencia, la psiquis de la mujer? ${ }^{45}$. Y, a pesar de que el diputado Juarros desmontó la supuesta cientificidad de dicha aseveración, los términos de la enmienda provocaron un ambiente de chanza y bromas, ante el cual la diputada Campoamor reaccionó seria y duramente ${ }^{46}$. El segundo, algo más cauto, planteaba su enmienda bajo el argumento de que la Repú-

${ }^{42}$ Recoge una buena síntesis del mismo ÁLVAREZ BERTRAND, P; El Tribunal de Garantías Constitucionales como órgano de tutela de los derechos fundamentales, KRK Ediciones, Oviedo, 2017, pág. 70 y ss.

${ }^{43}$ En todo caso de intenso y vibrante. «Enconado» es el término que emplea SÁNCHEZ AGESTA, L; Historia del Constitucionalismo Español (1808-1936), CEC, Madrid, 1974, pág. 594.

${ }^{44}$ Apéndice 9 al Diario de Sesiones, n. ${ }^{\circ}$ 46, de 29 de septiembre de 1931.

${ }^{45}$ Claro que estas manifestaciones no eran sino la continuación de una forma de pensar algo extendida en la época, también reflejada en sede parlamentaria por tesis como la de Novoa Santos, que abogaba por la natural y estructural histeria femenina. Vid. ARESTI, N; «Los argumentos de la exclusión: mujeres y liberalismo en la España contemporánea». En CASTELLS, I (coord); Mujeres y Constitucionalismo histórico español. Seis estudios., In Itinere-CEPC, Oviedo, 2014, pág. 41 y ss.

${ }^{46}$ VÁLCARCEL, A; op. cit., págs. 35 y 36. 
blica podría peligrar en caso de reconocimiento del sufragio femenino debido a la todavía enorme influencia que la Iglesia tenía sobre las mujeres españolas; en ese sentido, su voto «lógico» sería el voto por opciones de derechas y estas no dudarían en acabar con el frágil régimen republicano que se estaba intentando instaurar ${ }^{47}$; por todo ello, Guerra de Río defendía «que se reserve la República el derecho (de sufragio femenino) para concederlo en una ley electoral, para negarle al día siguiente si la mujer vota con los curas y la reacción».

La opción de Campoamor es clara y rotunda; defiende el voto de la mujer desde la óptica del principio democrático, ya que a su juicio nadie que ostente firmes convicciones democráticas puede argumentar seriamente que aquel deba limitarse por tratarse de ellas. Además, no deja de señalar la paradoja que supone el hecho de que fuera la dictadura la que atrajo a la mujer y estuviera siendo la República la que la rechazara. No tuvo mucha suerte en esta empresa ya que su propio partido la abandona y, junto a Acción Republicana y el Partido Radical Socialista, defiende la enmienda de Guerra del Río: la débil República debía ser cuidada y mimada, eliminando cualquier elemento que pudiera sentar las bases de su destrucción, siendo el voto femenino visto como un potencial peligro para la misma. A pesar de que en estos momentos Clara Campoamor tuvo algunos apoyos (diputados Beunza y Cordero), sí que parece que fue de las escasas defensas sinceras y comprometidas de tal derecho, máxime cuando planeaban sobre la cuestión intereses electorales de primer orden: las opciones de derechas veían un potencial caladero de votos proveniente del sector femenino, así como los socialistas, deseosos de atraer para sus dominios el voto obrero femenino. Se procede a la votación de la enmienda de Guerra del Río: 153 votos en contra, 93 a favor; el derecho de voto de las mujeres había dado un pequeño gran paso para su plasmación final en la futura Constitución pero todavía quedaban algunos flecos por cerrar.

El momento álgido llegará con el debate parlamentario que tiene lugar el 1 de octubre de $1931^{48}$. La síntesis de lo que en dicha sede se

${ }^{47}$ En el año 1932 Azaña escribía sobre el miedo a las elecciones parciales, miedo que también venía desde "las derechas, porque no quieren elecciones sin voto femenino, en el que ponen grandes esperanzas». Vid. AZAÑA, M; «Diarios»; en AZAÑA, M (edición de JULIÂ, S); Obras Completas, vol. 4, CEPC, Madrid, 2007, pág. 555.

${ }^{48}$ De nuevo testigo privilegiado, Azaña calificó la situación de «mucho griterío», y el «combate oratorio» entre ambas «muy divertido». En lo tocante a lo principal, Azaña dejó escrito esto: "Yo creo que tiene razón la Campoamor y que es una atrocidad negar el voto a las mujeres por la sospecha de que no votarían a favor de la República». Vid. AZAÑA, M; «Diarios»; en AZAÑA, M (edición de JULIÁ, S); Obras Completas, vol. 3, CEPC, Madrid, 2007, págs. 748 y 749.

(c) UNED. Revista de Derecho UNED, núm. 22, 2018 
dijo proviene de las dos posturas ligadas al reconocimiento del sufragio femenino, plasmadas en los argumentos de Victoria Kent y Clara Campoamor. Al primero se le puede denominar el «argumento ideológico»: la mujer era una ciudadana que merecía la misma consideración política que el hombre; negarle el derecho a voto era una actitud antidemocrática que entraba en contradicción con principios sustanciales del régimen republicano. Esta era, como se ha visto, la opción defendida por Campoamor y también por la mayoría de diputados socialistas. Por otro lado se aludía al «argumento de oportunidad»: políticamente es inoportuno conceder el derecho de sufragio a la mujer porque de forma casi automática ésta, a la hora de ejercerlo, se inclinará por partidos conservadores debido a la influencia de los sectores católicos sobre ella, los cuales aprovecharían para laminar la II República. De ahí que los defensores de esta postura aboguen por limitar o directamente negar tal derecho. La mujer no estaba todavía preparada para ejercer el derecho de sufragio sin poner en peligro aquélla ${ }^{49}$.

Todos los diputados se alinearon en torno de alguna de esas dos posturas: por un lado, aquellos partidarios de conceder el sufragio a la mujer, constitucionalmente y sin limitaciones, entre los que se contaban esos socialistas (excepto el sector liderado por Indalecio Prieto, el cual llegó a decir que la concesión del voto femenino era una «puñalada trapera a la República ${ }^{50}$ ), los partidos de derechas y Clara Campoamor. Ya hemos señalado que tanto esta como los socialistas defendían el sufragio femenino desde una perspectiva ideológica. Quizás, las dudas se centraban en los partidos de derechas y en sus motivos. No queda tan claro que tuvieran en mente principios ideológicos (libertad política, liberación femenina, igualdad de género) cuando defendían el sufragio femenino incondicionado, sino que quizás tenían la vista puesta en unas relativamente cercanas elecciones, en las cuales podría ser decisivo el voto de la mujer para alcanzar la victoria. Desde luego, los partidos de derechas seguían teniendo una visión tradicional y conservadora de la mujer. Y quizás estaban dispuestos a ceder, renunciar a dichos principios por interés electoral. Opinión que se refuerza observando un dato revelador. En el debate del día 1 de

\footnotetext{
${ }^{49}$ La relación entre los púlpitos, la derecha y la mujer era constatable (aunque lejos de tener la capacidad de influencia electoral que se le atribuía). En pleno debate, Gil Robles, jefe de la CEDA, entrega en el Congreso un millón de firmas femeninas pidiendo la protección de los institutos religiosos, lo que es utilizado como argumento por Guerra del Río para demostrar hasta qué punto la mujer estaba dirigida en sus pensamientos por los sectores católicos y derechistas. VALCÁRCEL, A; «El debate...» op. cit., págs. 38-40.
}

50 ÁLVAREZ-PIÑAR, M; (y otras), op. cit, pág. 81. 
octubre, ninguno de esos diputados defendió los motivos por los que estaban a favor del sufragio femenino.

El segundo grupo de diputados lo formaban aquellos que creían que era necesario diferenciar el voto según los sexos, condicionando el femenino para mantener con vida al régimen republicano. Creen de justicia que la naciente Carta Magna les reconozca personalidad política a las mujeres, pero sometida a determinados requisitos y condiciones. Quienes así pensaban, ya se ha dicho, eran los radicales, los radical-socialistas y Acción Republicana, teniendo como defensora de estos argumentos a la diputada y también Directora General de Instituciones Penitenciarias, Victoria Kent.

Se ha resumido muy bien el asunto cuando se ha dicho que la situación era la de «una izquierda que consideraba el voto femenino como un derecho pero temía las consecuencias políticas de su ejercicio y una derecha que tendía a recusar ese derecho pero esperaba obtener beneficios electorales de su reconocimiento» ${ }^{51}$.

Las espadas estaban en todo lo alto y el ambiente mostraba tensión acumulada y nerviosismo a partes iguales. La tribuna pública del Congreso estaba repleta de mujeres, prestas a apoyar a los defensores del sufragio y a abuchear a todos los que se opusieran. Además, la Asociación Nacional de Mujeres Españolas distribuyó unos panfletos en los cuales se pedía el apoyo al sufragio femenino por parte de los «Sres. diputados ${ }^{52}$.

El intercambio dialéctico se presentaba emocionante. Kent aboga no por condicionar el voto, sino por aplazarlo. Es cuestión de oportunidad política para la II República. Negar el voto le parece injusto. Campoamor replica que sólo hay una cosa que tener en cuenta una cuestión: la «justicia» y la «igualdad ante la ley», es decir, el principio democrático. Además, esta añade que «es un problema de ética, de pura ética reconocer a la mujer, ser humano, todos sus derechos $»^{53}$.

Pero no sólo son las dos mujeres las que hablan en el Congreso. Expondrán sus pareceres aquellos diputados posicionados tanto en contra como a favor del sufragio femenino, con la consabida excepción de los diputados de los partidos de derechas.

${ }^{51}$ Vid. PÁEZ-CAMINO, F; La Constitución republicana de 1931 y el sufragio femenino, UMER, Madrid, 2007, pág. 9.

${ }^{52}$ Dicho panfleto es recogido por Clara Campoamor en su obra autobiográfica. Vid. CAMPOAMOR, C; Mi pecado mortal: el voto femenino y yo, Instituto Andaluz de la Mujer, Sevilla, 2001.

${ }^{53}$ Diario de Sesiones n. ${ }^{\circ}$ 48, de 1 de octubre de 1931, pág. 1353. 
Respecto a los primeros, el diputado Guerra del Río hace gala de una incisiva oratoria, al decir que, en el caso de la concesión del voto femenino sin límites, «los republicanos no respondemos de la República» ${ }^{54}$. A pesar de que intenta, una vez más, retirar el artículo referido, no lo consigue. También el diputado Galarza, compañero de Kent, muestra una línea parecida al anterior, aludiendo a las dificultades para el régimen republicano, caso de conceder sin límites el voto a las mujeres.

En cuanto a los diputados que apoyan el sufragio, destacan las intervenciones de Ovejero (socialista), Castrovido (de Acción Republicana, aunque deja claro que piensa y vota diferente a la línea marcada por su partido) y Companys (ERC). Las tres intervenciones dejan entrever una interesante y, en cierta medida, novedosa reflexión en relación con el sufragio femenino: este no supone ningún peligro para la República, antes al contrario, su plasmación supondría implicar directamente a la mujer en la construcción de la República, "aún a costa de perder unos escaños». A pesar de que se podía extraer de dicho razonamiento la más que probable vinculación entre mujer-catolicismo-voto, un sector de los defensores de su implantación total y acondicionada veían en el mismo el comienzo de una provechosa educación política para el régimen, laica y republicana.

Llega el momento de la votación nominal. A lo largo de la misma, aquellos diputados que votaban en contra sufrían los descalificativos y abucheos de la tribuna del Congreso, repleta de mujeres deseosas de ver plasmado en el texto constitucional el sufragio femenino sin condicionante alguno. Indalecio Prieto, Ministro de Hacienda, y sus acólitos, abandonan el hemiciclo ante lo que ellos ven poco menos que como una traición a la República, a pesar de que los buenos oficios del diputado Galarza consiguen reconducir la decisión de alguno de estos parlamentarios, que regresan a sus escaños y votan. El resultado final es claro, aunque en cierta medida exiguo: 161 votos a favor y 121 en contra. Las tres primeras fuerzas que votaron a favor fueron los socialistas (82 votos), el Partido Agrario (13 votos) y el Partido Republicano-Conservador (con 11 sufragios). Los votos en contra se distribuyeron mayoritariamente, como no podía ser de otra manera, entre radicales, radical-socialistas y miembros de Acción Republicana, con 50, 28 y 17 votos en contra, respectivamente. Pero era un hecho que el sufragio femenino había conseguido triunfar. El artículo 34, el 36 en la redacción definitiva del texto constitucional, reflejaba la igual-

${ }^{54}$ Diario de Sesiones n. ${ }^{\circ}$ 47, de 1 de octubre de 1931, pág. 1342. 
dad política entre hombres y mujeres. Los argumentos de Clara Campoamor habían cosechado éxito.

Por poner algún pero, la principal tacha fue el escaso interés que suscitó en la Cámara el asunto del voto femenino. A pesar de lo que pudiera parecer, en esta votación final, de un total de 470, 188 diputados no asistieron a la votación, mientras que el $40 \%$ de los parlamentarios ni siquiera asistieron al hemiciclo.

Ahora bien, ¿era este triunfo definitivo?

\section{III.2.C. El último envite}

El artículo 36 quedaba así redactado: «Los ciudadanos de uno y otro sexo, mayores de 23 años, tendrán los mismos derechos electorales, conforme determinen las leyes». España se alineaba junto a los países que habían incorporado la igualdad y, en particular, el sufragio femenino, en sintonía con las Constituciones que servían de modelo a la nuestra (en concreto la de México de 1917 y, sobre todo, la de la República de Weimar de 1919). Era, en definitiva, sumarse al grupo de esos Parlamentos democráticos de las naciones más avanzadas ${ }^{55}$.

Pero los defensores de la limitación del sufragio femenino no se dieron por vencidos. Aprovechando que se había abierto el plazo para la presentación de disposiciones transitorias, el diputado de Acción Republicana Matías Peñalba presenta, el 21 de noviembre, una disposición que se puede resumir en los siguientes términos: «El derecho de sufragio acordado a la mujer por el artículo 36 de esta Constitución será efectivo en las primeras elecciones municipales que se celebren. Para las legislativas el sufragio femenino no entrará en vigor hasta después de haberse llevado al efecto totalmente la renovación de los actuales Ayuntamientos» ${ }^{56}$. Lo que se pretendía era diferir el sufragio de la mujer, posponerlo en el tiempo. La polémica estaba de nuevo servida. Y calculadamente: las derechas -que recordemos habían votado a favor del sufragio femenino- se habían retirado del Congreso (en protesta por el tratamiento parlamentario y gubernamental de la cuestión religiosa). En aquel momento se calculaba que habría veinte votos menos favorables al sufragio femenino. Los planteamientos limitadores podían triunfar, existía un atisbo de esperanza.

${ }^{55}$ Por todos, véase CASANOVA, J; «República y guerra civil». En FONTANA, J; y VILLARES, R (dirs.); Historia de España, Crítica-Marcial Pons, Madrid, 2007, vol. 8, pág. 32.

${ }^{56}$ Apéndice n. ${ }^{\circ} 11$ del Diario de Sesiones, n. ${ }^{\circ}$ 80, de 25 de noviembre de 1931. 
Fuera del Parlamento, las calles seguían dando cuenta de la lucha sufragista. Un grupo de mujeres presentó un escrito al Congreso de los Diputados el 25 de noviembre, a través del cual querían dejar constancia de su disconformidad e indignación por este nuevo intento de coartar la libertad e igualdad política femenina. Además, dicha disposición atenta contra el que ya es letra y espíritu de la Constitución, plasmado en el artículo 25 (no existe privilegio jurídico alguno por motivo de sexo) y en el artículo 36 (igualdad absoluta en el derecho de sufragio ${ }^{57}$. Ello no fue impedimento para que el diputado Terrero presentara una disposición proponiendo aplazar el voto para aquellas mujeres que no sean viudas o solteras mayores de edad, hasta 8 años después de establecida la nueva Ley Electoral. Ambas iniciativas fueron presentadas para su discusión en la Cámara el día 1 de diciembre de 1931. Finalmente, Terrero retira su disposición y se pasa a debatir la del diputado republicano Peñalba.

Desde la óptica de los argumentos barajados, las dos posturas principales no varían en casi nada; el diputado Peñalba defiende su disposición, alegando la posible repercusión práctica negativa del voto femenino, puesto que no se sabe cómo lo ejercerá la mujer, aunque se intuye que lo hará hacia otros sectores ideológicos contrarios al suyo. Y ello supone un grave peligro para la República. Clara Campoamor responde que ahora va a defender «la Constitución», puesto que el artículo 36 de la misma contempla dicho sufragio. Además, presenta una serie de datos que vienen a demostrar, ante el discutido argumento de que la mujer todavía no está preparada, que siguiendo esa lógica el hombre, o al menos ciertos hombres, también tendrían que tener vedado el derecho de voto. Denunciando la incoherencia, aconseja que no se delibere la enmienda. Llega el turno de palabra de aquellos que desean limitar el voto. Peñalba aboga por revisar la Constitución en un caso tan importante, Barriobero opta por no permitir el voto a las mujeres casadas, monjas y prostitutas. Guerra del Río sigue insistiendo que su partido defiende la igualdad de sexos, pero que otorgar el sufragio femenino sin límites supondría un grave peligro para la República.

El sector parlamentario favorable al voto femenino sin límites (socialistas y Clara Campoamor, debido a la ausencia parlamentaria ya comentada de los sectores de derechas) observa cómo los defensores del aplazamiento padecen un «biologismo oculto» (diputado Balbontín) además de observar el voto femenino como un derecho establecido y no concedido, estando ligada esta última concepción a una cuestión de incapacidad política de la mujer, rechazable de todo punto

${ }^{57}$ El texto se encuentra en CAMPOAMOR, C; op. cit., págs. 194-195. 
(argumento defendido por el diputado Cordero). Además, Juarros destaca la variedad ideológica que anida en la mujer, como en el hombre, lo cual invalidaría el argumento de la ideología católico-conservadora de la mujer española. En fin, el diputado Gómez-Paratcha, también se posiciona en contra de la disposición transitoria presentada por Peñalba.

Las fuerzas están muy justas. El presidente de la Cámara dispone que sus señorías procedan a llevar a cabo la votación, la cual fue también nominal. El resultado es realmente apretado: 127 votos a favor de la transitoria, por 131 a favor en contra. Por tan solo cuatro votos, el sufragio femenino queda definitivamente establecido en el artículo 36 de la Constitución Republicana de 1931. La lucha y perseverancia de los socialistas y de Clara Campoamor ha dado sus frutos. La mujer española gozará del derecho de sufragio sin limitación alguna, reconociéndose este al máximo nivel jurídico: en la Carta Magna.

\section{EL FIN DE LA II REPÚBLICA Y EL FIN DEL SUFRAGIO FEMENINO}

Lo que sucedió después es cosa sabida, demostrando que los que creían que el voto femenino destruiría la República estaban equivoca$\operatorname{dos}^{58}$. Al menos lo estaban por dos motivos. El primero, que la República tuvo que lidiar con muchos más problemas que ese, y de no poca envergadura; la confluencia en el tiempo de varios de ellos; la actitud de buena parte de actores políticos; la tensión social ligada a la cuestión religiosa; el malestar dentro de los Ejércitos, lo convulso del ambiente social... En fin, fueron múltiples las causas que actuaron conjuntamente para contribuir a su caída ${ }^{59}$. Y el segundo, que la fluctuación de dicho voto es una realidad y no ese monolito dirigido desde hogares y púlpitos, puesto que mientras que en 1933 triunfaron las derechas, en 1936 lo hicieron las izquierdas ${ }^{60}$.

${ }^{58}$ Razona lo exagerado del tal diagnóstico PÁEZ CAMINO, F; op. cit, págs. 13 y 14.

${ }^{59}$ Haciendo hincapié en las causas endógenas encontramos a VACA DE OSMA, J.A; op. cit. págs. 371-422. Respecto a las causas e influencias exógenas puede verse PRESTON, P (ed); La República asediada. Hostilidad internacional y conflictos internos durante la Guerra Civil. Península, Barcelona, 2001. Ver también AGUILAR GAVILÁN, E; "La II República: Mito y realidad»; Boletín de la Real Academia de Córdoba de Ciencias, Bellas Letras y Nobles Artes, n. ${ }^{\circ}$ 165, 2016, págs. 69-87. Desde una perspectiva sintética pero ilustrativa, FUSI, J.P; Historia mínima de España, Turner, Madrid, 2012, págs. 217-220.

${ }^{60} \mathrm{Vid}$. VACA DE OSMA, J.A; Historia de España para jóvenes del siglo XXI, Ediciones Rialp, Madrid, 2010 (4. . edición), págs. 382 y 388; PÁEZ-CAMINO, F; op. cit, pág. 12 y ss; y MONTERDE GARCÍA, J.C; op. cit, pág. 276.

(c) UNED. Revista de Derecho UNED, núm. 22, 2018 
Sea como fuere, el régimen republicano reconoció la igualdad entre sexos, en concreto, que la mujer estaba en igualdad de condiciones respecto al hombre en todos los ámbitos ${ }^{61}$. La prematura destrucción de aquél no nos ha permitido llevar a cabo un juicio sereno y fundado sobre el desarrollo del principio igualitario bajo las directrices republicanas; la Guerra Civil finaliza con el triunfo del bando nacional y la posterior instauración del régimen franquista, sin que existiera la posibilidad de profundizar en el postulado igualitario ${ }^{62}$.

Como último apunte, resaltar que a lo largo del periodo franquista se puede contar cierta participación política femenina, en todo caso canalizada desde arriba. De ese modo, la Sección Femenina de la Falange fue la única asociación legalizada que permitió a la mujer —ese «angel del hogar», por otro lado- acceder a la política y a otros campos vitales como el cultural o laboral. Ello provocó que las Cortes orgánicas tuvieran entre sus miembros a algunas Procuradoras a lo largo de sus diez Legislaturas, con cifras testimoniales que en ningún caso superaron el 1,5\% del total de representantes ${ }^{63}$.

En el periodo que va desde 1942 hasta 1975, las mujeres gozaron del derecho de sufragio, aunque convenientemente limitado ${ }^{64}$. Gozaron de este en las elecciones sindicales, y desde 1968, podían ser elegidas concejales y miembros de Corporaciones Provinciales (siempre y cuando fueran mujeres casadas, o cabezas de familia). También éstas podrían elegir y ser elegidas para ostentar cualquiera de los dos cargos de Procurador de Familia que cada provincia seleccionaba. En suma, fueron trece las Procuradoras en Cortes: cinco elegidas directamente (precisamente, de ése grupo de representantes familiares); dos seleccionadas como Consejeras Nacionales por las provincias; tres designadas por el Jefe Nacional; una Procuradora

${ }^{61}$ LÓPEZ DE LOS MOZOS DÍAZ-MADROÑERO, A; «Igualdad de género en la Segunda República: la obtención del voto femenino y otras medidas a favor de la igualdad». En GORDILLO, L; MARTÍN, S; y VÁZQUEZ, V (Dirs.); Constitución de 1931: estudios jurídicos sobre el momento republicano español, Marcial Pons, Madrid, 2017, pág. 351 y ss.

${ }^{62}$ Son muchos los estudios que subrayan la importancia que tuvo para el régimen republicano el principio igualitario y la no discriminación por razón de sexo. Por todos, ver CLAVERO, B; op. cit, p. 198 y ss; y VARELA SUANZES-CARPEGNA, op. cit, pág. 622 y ss;

${ }^{63}$ FRANCO RUBIO, G. A; «De la vida doméstica a la presencia pública: las mujeres en las Cortes franquistas», en PÉREZ CANTÓ, P; (ed.); De la democracia ateniense a la democracia paritaria, Icaria, Barcelona, 2009, págs. 187-207.

${ }^{64}$ Vid. RUIZ DE AZÚA ANTÓN, M. A; Las elecciones a las Cortes de Franco: 19421975, (3 vol.); Tesis Doctoral inédita, Madrid, junio de 1987; y FIGUERUELO BURRIEZA, A; op.cit, pág. 154 y ss. 
sindical por razón del cargo; otra alcaldesa elegida en un municipio de más de 300.000 habitantes; y, por último, una Procuradora sindical elegida por la Asamblea Sindical.

Será la Constitución de 1978 la que vuelva a traer la igualdad plena en el reconocimiento y ejercicio del derecho de sufragio activo y pasivo $^{65}$. Pero esa historia, con sus propias luces y sombras en lo que hace a la igualdad de género, merecería discusión aparte ${ }^{66}$.

\section{CONCLUSIONES}

Como conclusiones cabría destacar las siguientes.

La primera es que el caso español confirma que, sin tener un movimiento sufragista especialmente intenso, la voluntad política de unos pocos y de unas pocas pusieron los mimbres para la consecución del voto femenino.

La segunda es que, aunque tarde, el sufragio femenino acaba llegando a nuestra latitud. Y acaba llegando gracias a un clima político propicio para la democracia y las libertades, al menos para poder discutir sobre las mismas; así lo muestran quienes lucharon en sede parlamentaria por su consecución, destacando especialmente las labores de Clara Campoamor. Con todo, el asunto no fue de los considerados vitales (al menos no en sede parlamentaria).

La tercera es que el sufragio femenino llega venciendo bastantes resistencias y trabas, provocadas por multitud de recelos y prejuicios. En 1931 coexistieron en este tema posturas ideológicas y posturas estratégicas tanto a favor como en contra, lo cual cuestionaba algunos tópicos sobre esa sempiterna visión de la izquierda como defensora, más bien redentora, de la igualdad.

${ }^{65}$ Por todos, vid. ALZAGA VILLAAMIL, Ó; Comentario Sistemático a la Constitución Española de 1978, Marcial Pons, Madrid, 2016 (2. edición), pág. 186 y ss.

${ }^{66}$ Desde el mismo momento en el que llega la Ley para la Reforma Política, el movimiento feminista español se divide entre quienes defienden ganar espacios de forma gradual y quienes abogan por no jugar al juego patriarcal, base de todo el edificio institucional. Vid. VENTURA FRANCH, A; "Constitución y Género: un relación compleja». En BALAGUER CALLEJÓN, M. ${ }^{a} . L$ (ed); XXV Aniversario de la Constitución Española. Propuestas de reformas, CEDMA, Málaga, 2004, pág. 412 y ss; SCANLON, G.M; op. cit., pág. 97 y ss; y URIARTE, E; «Estudios de mujeres y política en España». En URIARTE E; y ELIZONDO, A (coords.); Mujeres en Política, Ariel, Barcelona, 1997, pág. 22 y ss. Recientemente, GÓMEZ FERNÁNDEZ, I; op. cit, pág. 69 y ss. 


\section{BIBLIOGRAFÍA}

Aguado, A; «Ciudadanía, mujeres y democracia», Historia Constitucional, n. ${ }^{\circ} 6$ (2005).

Aguilar Gavilán, E; «La II República: Mito y realidad»; Boletín de la Real Academia de Córdoba de Ciencias, Bellas Letras y Nobles Artes, n. ${ }^{\circ}$ 165, 2016.

ÁLVAREZ-PIÑAR, M (y otras); El voto femenino en España, Subdirección General de Cooperación-Instituto de la Mujer, Madrid, 1995.

Alzaga Villamil, Ó; La primera democracia cristiana en España, Ariel, Barcelona, 1973.

Alzaga Villaamil, Ó; Comentario Sistemático a la Constitución Española de 1978, Marcial Pons, Madrid, 2016 (2. ${ }^{a}$ edición).

Alzaga Villaamil, Ó; Sociedad democrática y Constitución, Marcial Pons, Madrid, 2018.

Álvarez Bertrand, P; El Tribunal de Garantías Constitucionales como órgano de tutela de los derechos fundamentales, KRK Ediciones, Oviedo, 2017.

Amorós, C; «Feminismo e Ilustración», en Capel, R (ed.); Historia de una conquista: Clara Campoamor y el voto femenino, Ayuntamiento de Madrid-Dirección General de la Mujer, Madrid, 2007.

ARESTI, N; «Los argumentos de la exclusión: mujeres y liberalismo en la España contemporánea». En Castells, I (coord); Mujeres y Constitucionalismo histórico español. Seis estudios., In Itinere-CEPC, Oviedo, 2014.

AzaÑa, M; «Diarios»; en Azaña, M (edición de Juliá, S); Obras Completas, vol. 3, CEPC, Madrid, 2007.

Azaña, M; «Diarios»; en Azaña, M (edición de Juliá, S); Obras Completas, vol. 4, CEPC, Madrid, 2007.

Blanco Corujo, O; Olimpia de Gouges (1748-1793). Madrid, Ediciones del Orto, 2000.

Campoamor, C; Mi pecado mortal: el voto femenino y yo, Instituto Andaluz de la Mujer, Sevilla, 2001.

CAPel Martínez, R; El sufragio femenino en la II República Española, Granada, Universidad de Granada, 1992.

Capel Martínez, R; "La conquista del voto femenino», Andalucía en la Historia, n. ${ }^{\circ}$ 13, 2006.

Casanova, J; República y guerra civil. En Fontana, J; y Villares, R (dirs.); Historia de España, Crítica-Marcial Pons, Madrid, 2007. 
Clavero, B; Manual de Historia Constitucional de España, Alianza, Madrid, 1992.

Сово, R; "Repensando la democracia: mujeres y ciudadanía», en Cobo, R (ed.); Educar en la ciudadanía. Perspectivas feministas, Los libros de la catarata, Madrid, 2008.

De Burgos, C; La mujer moderna y sus derechos, Ayuntamiento de Madrid, 2007; (1. ${ }^{a}$ edición: Editorial Sempere, 1927).

Durán y Lalaguna, P; El voto femenino en España, Asamblea de Madrid, Madrid, 2007.

Escudero Alday, R; «Las huellas del neoconstitucionalismo. Democracia, participación y justicia social en la Constitución Española de 1931». En Gordillo, L; Martín, S; y Vázquez, V (Dirs.); Constitución de 1931: estudios jurídicos sobre el momento republicano español, Marcial Pons, Madrid, 2017.

Figueruelo Burrieza, A; «Setenta y cinco años de sufragio femenino en España. Perspectiva constitucional». Criterio Jurídico, n. ${ }^{\circ} 7$, 2007.

Franco Rubio, G. A; «De la vida doméstica a la presencia pública: las mujeres en las Cortes franquistas», en Pérez Cantó, P; (ed.); De la democracia ateniense a la democracia paritaria, Icaria, Barcelona, 2009.

FusI, J.P; Historia mínima de España, Turner, Madrid, 2012.

García ATANCE, M. ${ }^{a} . \mathrm{V}$; «Crónica parlamentaria sobre la Constitución de 1931». Revista de Derecho Político, n. ${ }^{\circ}$ 12, 1981-1982.

García Canales, M; El problema constitucional en la Dictadura de Primo de Rivera, Centro de Estudios Constitucionales, Madrid, 1980.

Garrido Gómez, I; «Los movimientos feministas». En Carmona Cuenca, E (coord.); Diversidad de Género e Igualdad de Derechos, Tirant lo blanch, Valencia, 2012.

Gilbaja CABrero, E; «Clara Campoamor y el sufragio femenino en la Constitución de la Segunda República», Asamblea: Revista Parlamentaria de la Asamblea de Madrid, n. ${ }^{\circ}$ 29, 2013.

Gómez, Fernández, I; Una Constituyente feminista. ¿Cómo reformar la Constitución con perspectiva de género?, Marcial Pons-Fundación Manuel Giménez Abad, Madrid, 2017.

Juliá, S; La Constitución de 1931, Iustel, Madrid, 2009.

(C) UNED. Revista de Derecho UNED, núm. 22, 2018 
Marrades Puig, A; «Los derechos políticos de las mujeres: evolución y retos pendientes», Cuadernos de la Cátedra Fadrique Furió Ceriol, n. ${ }^{\circ} 36 / 37,2001$.

Mendus, S; «La pérdida de la fe: feminismo y democracia», en Dunn, J (Dir.); Democracia. El viaje inacabado (508 a.C-1993 d.C), Tusquets, Barcelona, 1995.

Miyares, A; «El sufragismo», en Amorós, C y De Miguel, A (eds.) Teoría feminista: de la Ilustración a la globalización. De la Ilustración al segundo sexo, Minerva, Madrid, 2005.

Monterde García, J.C; «Algunos aspectos sobre el voto femenino en la II República española: debates parlamentarios», Anuario de la Facultad de Derecho, n. ${ }^{\circ}$ 28, 2010.

Oliver Araujo, J; El sistema politico de la Constitución Española de 1931, Ediciones UIB, Palma de Mallorca, 1999.

Páez-Camino, F; La Constitución republicana de 1931 y el sufragio femenino, UMER, Madrid, 2007.

Peña González, J; «El voto femenino», Real Academia de Córdoba de Ciencias, Bellas Letras y Nobles Artes, n. . 160, 2011.

Pérez Garzón, J.S; Historia del Feminismo, Libros de la Catarata, Madrid, 2011.

Pérez-Prendes Muñoz-Arraco, J.M; Escritos de Historia Constitucional Española, Marcial Pons, Madrid, 2017.

Pérez Serrano, N; La Constitución Española, 9 diciembre 1931: Antecedentes, Texto, Comentarios, Editorial Revista de Derecho Privado, Madrid, 1932.

PosadA, A; Feminismo, Ediciones Cátedra, Oviedo, 1994 (1. ${ }^{a}$ edición: Ricardo Fe, Madrid, 1899).

Preston, P (ed); La República asediada. Hostilidad internacional y conflictos internos durante la Guerra Civil. Península, Barcelona, 2001.

Ramírez Jiménez, M; Las reformas de la II República, Túcar, Madrid, 1977.

Ruiz de Azúa AnTón, M. A; Las elecciones a las Cortes de Franco: 19421975, (3 vol.); Tesis Doctoral inédita, Madrid, junio de 1987.

SÁnchez Agesta, L; Historia del Constitucionalismo Español (18081936), CEC, Madrid, 1974. 
Sánchez Collantes, S; «Antecedentes del voto femenino en España: el republicanismo federal pactista y los derechos políticos de las mujeres (1868-1914)»; Historia Constituciónal, n. ${ }^{\circ} 15$ (2014).

SCANLON, G.M; «El movimiento feminista en España, 1900-1985: logros y dificultades». En ASTELARRA, J (comp); Participación política de las mujeres, CIS, Madrid, 1990.

Sevilla Merino, J; Mujeres y ciudadanía: la democracia paritaria, Institut Universitari d'Estudis de la Dona-Universitat de València, 2004.

StUART Mill, J; Libertad. Gobierno representativo. Esclavitud femenina, Tecnos, Madrid, 1969.

StUart Mill, J; El sometimiento de la mujer, Alianza Editorial, Madrid, 2010.

Tomás Vilarroya, J; Breve historia del constitucionalismo español, CEPC, Madrid, 2012 (13. ${ }^{\text {a }}$ edición).

Torres del Moral, A; Constitucionalismo histórico español, Servicio de Publicaciones de la Facultad de Derecho-UCM, Madrid, 2004 (5. ${ }^{\mathrm{a}}$ edición).

Torres Muro, I; «La educación en tres momentos constitucionales (1812, 1931, 1978)», Revista Española de Pedagogía, n. ${ }^{\circ}$ 253, 2012.

URIARTE, E; «Estudios de mujeres y política en España». En Uriarte E; y Elizondo, A (coords.); Mujeres en Política, Ariel, Barcelona, 1997.

VACA DE Osma, J.A; Historia de España para jóvenes del siglo XXI, Ediciones Rialp, Madrid, 2010 (4. ${ }^{a}$ edición).

VÁlCARCEL, A; «El voto femenino en España. La Constitución del 31 y Clara Campoamor». Estudio Preliminar en El debate sobre el voto femenino en la Constitución de 1931, Congreso de los Diputados. Madrid, 2002.

VALCÁRCEL, A; «La memoria colectiva y los retos del feminismo», Naciones Unidas, Serie Mujer y desarrollo, n. ${ }^{\circ}$ 31, 2001, p. 8.

VAlCÁRCel, A; Sexo y filosofía. Sobre «mujer» y "poder», Anthropos, Barcelona, 1994.

Varela Suanzes-Carpegna, J; Política y Constitución en España (18081978), CEPC, Madrid, 2014 (2. ${ }^{\text {a }}$ edición).

Ventura Franch, A; "Constitución y Género: un relación compleja». En Balaguer Callejón, M. ${ }^{\mathrm{a}}$.L (ed); XXV Aniversario de la Constitución Española. Propuestas de reformas, CEDMA, Málaga, 2004. 
Vera Santos, J.M; Las Constituciones de España. Constituciones y otras leyes y proyectos políticos de España. Thomson-Civitas, Cizur Menor (Navarra), 2008.

Villalaín, P; Las elecciones municipales de 1931 en Madrid, El Avapiés, Madrid, 1987.

VVAA; Estudios sobre la II República Española, Tecnos, Madrid, 1975.

Wollstonecraft, M; Vindicación de los derechos de la mujer, Istmo, Madrid, 2005. 